\title{
Feasibility and safety of colonoscopy performed by nonexperts for acute lower gastrointestinal bleeding: post hoc analysis
}

\section{다 $(1)=$}

\section{Authors}

Tsutomu Nishida ${ }^{1}$, Ryota Niikura ${ }^{2,3}$, Naoyoshi Nagata ${ }^{3,4}$, Tetsuro Honda ${ }^{5}$, Hajime Sunagozaka ${ }^{6}$, Yasutoshi Shiratori ${ }^{7}$, Shigetsugu Tsuji ${ }^{8}$, Tetsuya Sumiyoshi ${ }^{9}$, Tomoki Fujita ${ }^{10,11}$, Shu Kiyotoki ${ }^{12}$, Tomoyuki Yada ${ }^{13}$, Katsumi Yamamoto ${ }^{14}$, Tomohiro Shinozaki $^{15}$, Dai Nakamatsu ${ }^{1}$, Atsuo Yamada², Mitsuhiro Fujishiro ${ }^{16}$

Institutions

1 Department of Gastroenterology, Toyonaka Municipal Hospital, Toyonaka-shi, Osaka, Japan

2 Department of Gastroenterology, Graduate School of Medicine, The University of Tokyo, Tokyo, Japan

3 Gastroenterological Endoscopy, Tokyo Medical University, Shinjuku-ku, Tokyo, Japan

4 Department of Gastroenterology and Hepatology, National Center for Global Health and Medicine, Shinjuku-ku, Tokyo, Japan

5 Department of Gastroenterology, Nagasaki Harbor Medical Center, Nagasaki-shi, Nagasaki, Japan

6 Department of Gastroenterology, Fukui Prefectural Hospital, Fukui-shi, Fukui, Japan

7 Department of Gastroenterology, St. Luke's International Hospital, Chuo-ku, Tokyo, Japan

8 Department of Gastroenterology, Ishikawa Prefectural Central Hospital, Kanazawa-shi, Ishikawa, Japan

9 Department of Gastroenterology, Tonan Hospital, Sapporo-shi, Hokkaido, Japan

10 Department of Gastroenterology, Otaru Ekisaikai Hospital, Otaru-shi, Hokkaido, Japan

11 Department of Gastroenterology, Sapporo Century Hospital, Sapporo-shi, Hokkaido, Japan

12 Department of Gastroenterology, Shuto General Hospital, Yanai-shi, Yamaguchi, Japan

13 Department of Gastroenterology and Hepatology, National Center for Global Health and Medicine Kohnodai Hospital, Ichikawa-shi, Chiba, Japan

14 Department of Gastroenterology, Japan Community Healthcare Organization Osaka Hospital, Osaka-shi, Osaka, Japan

15 Department of Information and Computer Technology, Faculty of Engineering, Tokyo University of Science, Tokyo, Japan

16 Department of Gastroenterology and Hepatology, Nagoya University Graduate School of Medicine, Nagoya-shi, Aichi, Japan

submitted 15.12.2020

accepted after revision 2.3.2021
Bibliography

Endosc Int Open 2021; 09: E943-E954

DOI 10.1055/a-1464-0809

ISSN 2364-3722

(C) 2021. The Author(s).

This is an open access article published by Thieme under the terms of the Creative Commons Attribution-NonDerivative-NonCommercial License, permitting copying and reproduction so long as the original work is given appropriate credit. Contents may not be used for commercial purposes, or adapted, remixed, transformed or built upon. (https://creativecommons.org/licenses/by-nc-nd/4.0/)

Georg Thieme Verlag KG, Rüdigerstraße 14,

70469 Stuttgart, Germany

Corresponding author

Tsutomu Nishida, PhD, MD, Department of Gastroenterology, Toyonaka Municipal Hospital, 4-14-1 Shibahara, Toyonaka, Osaka 560-8565, Japan

Fax: +81-6-6858-3531

tnishida.gastro@gmail.com

\section{ABSTRACT}

Background and study aims It remains unclear whether the experience of endoscopists affects clinical outcomes for acute lower gastrointestinal bleeding (ALGIB). We aimed to determine the feasibility and safety of colonoscopies performed by nonexperts using secondary data from a randomized controlled trial for ALGIB.

Patients and methods We analyzed clinical outcomes in 159 patients with ALGIB who underwent colonoscopies performed by two groups of endoscopists: experts and nonexperts. We compared endoscopy outcomes, including identification of stigmata of recent hemorrhage (SRH), successful endoscopic treatment, adverse events (AEs), and clinical outcomes between the two groups, including 30-day rebleeding, transfusion, length of stay, thrombotic events, and 30-day mortality.

Results Expert endoscopists alone performed colonoscopies in 96 patients, and nonexperts performed colonoscopies in 63 patients. The use of antiplatelets and warfarin was significantly higher in the expert group. The SRH identification rate (24.0 and $17.5 \%)$, successful endoscopic treatment rate $(95.0$ and $100 \%)$, rate of AEs during colonoscopy ( 0 and $0 \%)$, transfusion rate (6.3 and $4.8 \%$ ), length 
of stay ( 8.0 and 6.4 days), rate of thrombotic events ( 0 and $1.8 \%$ ), and mortality ( 0 and $0 \%$ ) were not different between the expert and nonexpert groups. Rebleeding within 30 days occurred more often in the expert group than in the nonexpert group (14.3 vs. $5.4 \% P=0.0914$ ).
Conclusions The performance of colonoscopies for ALGIB by nonexperts did not result in worse clinical outcomes, suggesting that its use could be feasible for nonexperts for diagnosis and treatment of ALGIB.

\section{Introduction}

Colonoscopy is essential for diagnosis and treatment of acute lower gastrointestinal bleeding (ALGIB). However, colonoscopy for ALGIB is an advanced and high-risk endoscopic procedure, and more training and experience are needed to maintain the quality and safety of colonoscopy for ALGIB than conventional colonoscopy. A previous retrospective study with 403 ALGIB patients showed that performance of the colonoscopy by an expert endoscopist was a significantly positive factor for the identification of stigmata of recent hemorrhage (SRH) diverticula, which is an important endoscopic outcome [1]. However, no available high-quality data on the effectiveness and safety of the performance of colonoscopies for ALGIB by nonexpert endoscopists in emergency settings have been reported. In addition, it is necessary to evaluate the associations between the number of years of experience and endoscopic and clinical outcomes in ALGIB patients. The latest colonoscopy core curriculum prepared by the American Society for Gastrointestinal Endoscopy Training Committee stated that a full discussion of the evaluation and treatment of lower gastrointestinal bleeding was beyond the scope of the document [2].

Recently, we performed a randomized controlled trial to evaluate the efficacy and safety of colonoscopy for ALGIB patients [3]. The trial had the largest sample size yet and was the first multicenter study involving nearly 100 endoscopists. In the present study, we performed a post hoc analysis of the trial data. This study was performed to investigate the feasibility of colonoscopy by nonexpert endoscopists in ALGIB patients.

\section{Patients and methods}

\section{Study subjects}

This study is a post hoc analysis from a multicenter randomized controlled trial (RCT) of early and elective colonoscopy for ALGIB that investigated the efficacy and safety of the former for patients with ALGIB $[3,4]$. Briefly, this RCT was an open-label study, and 170 patients aged $\geq 20$ years presenting with moderate-to-severe hematochezia or melena within 24 hours of arrival were randomly assigned (1:1) to either receive an early colonoscopy (within 24 hours of the initial visit to the hospital) or an elective colonoscopy (24-96 hours after hospital admission). The study was conducted at 15 hospitals in Japan from July 2016 until May 2018. Of the 170 enrolled patients, a total of 162 underwent randomization; three were excluded, and 159 were included in the modified intention-to-treat population. This post hoc analysis was approved by the institutional review boards of all participating hospitals.

\section{Colonoscopy and endoscopists}

All endoscopists were divided into two categories: experts and nonexperts. An expert endoscopist was defined as having conducted more than 1000 colonoscopies and as having performed endoscopic hemostasis, with board certification from the Japanese Gastroenterological Endoscopy Society (JGES); other endoscopists were considered nonexperts. We evaluated the years of experience with endoscopy. The selection of nonexpert endoscopists in an emergency setting depended on each institution's policy and patient background. This study protocol allowed a nonexpert endoscopist to perform a colonoscopy under the supervision of an expert endoscopist who provided verbal advice. When a nonexpert endoscopist met with difficulties or took longer to perform the procedure and when safety concerns for the patient arose, an expert endoscopist took over.

Colonoscopies were performed as video endoscopies (Fujifilm Corporation, Tokyo, Japan, or Olympus Optical, Tokyo) after oral bowel preparation with 2 to $4 \mathrm{~L}$ polyethylene glycolelectrolyte solution; an additional enema was allowed to be administered to patients in the case of inadequate bowel cleansing. The quality of bowel preparation was evaluated using the Aronchick scale [5]. The preparation quality was defined as adequate when excellent and good results were obtained.

An attachment cap and a water-jet device were used for all colonoscopy procedures. Attending physicians decided when to discontinue and resume medications such as nonsteroidal anti-inflammatory drugs, antiplatelet drugs, or anticoagulants.

\section{Endoscopic outcomes and clinical outcomes}

The endoscopic outcomes were the cecum insertion rate and time, completion rate of insertion by nonexperts alone, total procedure time, rate of identification of SRH, success rate of endoscopic treatment, completion rate of successful endoscopic treatment by nonexperts alone, need for additional endoscopic examinations, and colonoscopy-related adverse events (AEs). Clinical outcomes were the need for interventional radiology, need for surgery, need for transfusion during hospitalization, length of hospital stay, 30-day rebleeding rate, and 30-day mortality rate. Thirty-day rebleeding was defined as significant fresh blood in the stool after the initial colonoscopy with any of the following: 1) hemorrhagic shock; 2) need for transfusion; 3) identification of blood pooling on further colonoscopy; v) SRH in the lower gastrointestinal tract; or 5) extravasation identified in the colorectal region on contrast-enhanced computed tomography. 


\section{Statistical analysis}

Continuous variables were compared using Wilcoxon's ranksum test. Categorical variables were compared using the $X^{2}$ test or Fisher's exact test. $P$ value indicating statistical significance of the primary outcome was set at $<0.05$ for two-tailed tests.

As a sensitivity analysis, we performed a $1: 1$ propensity score-weighted analysis to balance covariates between the expert and nonexpert groups. A logistic regression model was used to calculate propensity scores for each patient in the group, including as covariates all of the following clinical characteristics: age, sex, body mass index, height, weight, level of hemoglobin, systolic and diastolic blood pressures, heart rate at admission, use of medications (NSAIDs, low-dose aspirin, thienopyridine, cilostazol, other antiplatelet drugs, warfarin, direct oral anticoagulants), and the presence of comorbidities (previous lower gastrointestinal bleeding, ischemic heart disease, chronic obstructive pulmonary disease, peptic ulcer, liver cirrhosis, diabetes mellitus, chronic heart failure, cerebrovascular disease, dementia, collagen disease, chronic kidney disease, leukemia, malignant lymphoma, solid tumors), and allocation to the early colonoscopy group.

As a subgroup analysis, we categorized the nonexpert group into two groups: <3 years of endoscopic experience and 3 to 6 years of endoscopic experience, according to the distribution of the obtained data (data not shown). We compared endoscopic and clinical outcomes between the group with $<3$ years of endoscopic experience and the expert group and between the group with 3 to 6 years of endoscopic experience and the expert group.

The statistical analyses were performed with SAS software v. 9.4 (SAS Institute, Cary, North Carolina, United States).

\section{Results}

\section{Baseline patient characteristics}

- Table 1 shows patient characteristics. The expert group performed colonoscopies in 96 patients, and the nonexpert group performed colonoscopies in 63 patients at the 12 participating hospitals. The expert group had a mean of 10.52 years of endoscopy experience and the nonexpert group had a mean of 4.32 years of experience.

The proportions of patients with ischemic heart disease (26\%), who used low-dose aspirin (31.3\%) and who used warfarin $(9.4 \%)$ in the expert group were significantly higher than those in the nonexpert group (7.9\%, 12.7\%, 1.6\%). However, the other comorbidities, medications, presence of hemodynamic instability, and hemoglobin levels were similar between the groups ( $\triangleright$ Table 1 ). Bleeding sources were similar in the two groups ( $>$ Table 2 ).

\section{Endoscopic outcomes and clinical outcomes}

- Table 2 shows endoscopic and clinical outcomes. Rates of adequate bowel preparation were $96.9 \%$ in the expert group and $100 \%$ in the nonexpert group, which were similar and sufficient. The cecum insertion rate was $95.8 \%$ in the expert group and $98.4 \%$ in the nonexpert group. The cecum insertion time of the expert group was significantly shorter than that of the nonexpert group $(8.1 \pm 5.8$ and $11.0 \pm 7.2$ minutes, $P=0.0061)$, but no significant difference in total procedure time was observed between the groups. The completion rate of insertion by nonexperts alone was $98.41 \%(62 / 63)$.

The identification rate for SRH did not differ between the two groups, and endoscopic findings of bleeding sources were similar between the groups. The success rate for endoscopic treatment and the need for additional endoscopic examinations were also no different between the groups. The completion rate for successful endoscopic treatment by nonexperts alone was $100 \%$ (63/63). Preparation-related AEs were similar between the groups and were not severe. With regard to colonoscopy-related AEs, hemorrhagic shock occurred in one patient $(1.0 \%)$ in the expert group and 0 patients in the nonexpert group. No perforation occurred in either group. Rebleeding within 30 days occurred in $14.3 \%$ of patients in the expert group and $5.4 \%$ of patients in the nonexpert group $(P=0.091)$. No difference was observed in the need for interventional radiology, surgery, or transfusion between the groups. The mean length of hospital stay was 8.0 days in the expert group and 6.4 days in the nonexpert group ( $\triangleright$ Table 2 ).

\section{Propensity score-weighted analysis}

Details of the baseline characteristics in each group after weighting are shown in $>$ Table 3. After weighting, there were no significant differences in cecum insertion rate, total procedure time, or bleeding sources between the two groups. There were no significant differences in SRH identification, successful endoscopic treatment rate, transfusion rate, length of stay, thrombotic events, 30-day rebleeding rate, or 30-day mortality rate between the two groups. AEs did not differ between the groups ( $\triangleright$ Table 4 ). These findings remained unchanged in the propensity score-weighted analysis.

\section{Subgroup analysis according to years of endoscopic experience}

Similarly, we compared endoscopic and clinical outcomes between the group with $<3$ years of endoscopic experience $(N=8$, - Table 5) and the expert group and between the group with 3 to 6 years of endoscopic experience $(\mathrm{N}=32$, $>$ Table 6$)$ and the expert group. The SRH identification rate was higher in the expert group than in both nonexpert groups; however, the differences were not significant. Endoscopic findings of the bleeding sources were similar between the expert group and both nonexpert groups. Colonoscopy-related AEs also were similar. Rebleeding within 30 days occurred more often in patients in the expert group than in either nonexpert group, and the length of stay was significantly longer in the expert group than in the nonexpert group with $<3$ years of experience $(\triangleright$ Table 5 , $>$ Table 6). 
- Table 1 Baseline patient characteristics.

\begin{tabular}{|c|c|c|c|}
\hline Characteristics & $\begin{array}{l}\text { Expert } \\
(N=96)\end{array}$ & Nonexpert $(N=63)$ & $P$ value \\
\hline Age (years), mean $\pm S D$ & $70.9 \pm 12.9$ & $69.6 \pm 12.1$ & 0.5383 \\
\hline Sex, male (\%) & $62(64.6)$ & $44(69.8)$ & 0.4915 \\
\hline Body mass index, mean $\pm S D$ & $23.5 \pm 4.1$ & $23.3 \pm 3.0$ & 0.7757 \\
\hline \multicolumn{4}{|l|}{ Comorbidities } \\
\hline - Previous lower gastrointestinal bleeding (\%) & $39(40.6)$ & $19(30.2)$ & 0.1799 \\
\hline - Charlson comorbidity index & $1.5 \pm 1.7$ & $1.2 \pm 1.9$ & 0.2943 \\
\hline - Ischemic heart diseases & $25(26.0)$ & $5(7.9)$ & 0.0043 \\
\hline - Chronic obstructive pulmonary disease & $2(2.1)$ & $1(1.6)$ & 0.8221 \\
\hline - Peptic ulcer & $5(5.2)$ & $3(4.8)$ & 0.8998 \\
\hline - Liver cirrhosis & $1(1.0)$ & $2(3.2)$ & 0.3336 \\
\hline - Diabetes mellitus & $18(18.8)$ & $9(14.3)$ & 0.4634 \\
\hline - Chronic heart failure & $8(8.3)$ & $1(1.6)$ & 0.0718 \\
\hline - Cerebral vascular diseases & $20(20.8)$ & $6(9.5)$ & 0.0593 \\
\hline - Dementia & $0(0.0)$ & $2(3.2)$ & 0.0789 \\
\hline - Collagen diseases & $7(7.3)$ & $2(3.2)$ & 0.2718 \\
\hline - Chronic kidney disease & $13(13.5)$ & $6(9.5)$ & 0.4449 \\
\hline - Leukemia & $1(1.0)$ & $0(0.0)$ & 0.4164 \\
\hline - Malignant lymphoma & $2(2.1)$ & $0(0.0)$ & 0.2489 \\
\hline - Solid cancer & $10(10.4)$ & $9(14.3)$ & 0.4619 \\
\hline - Metastatic cancer & $1(1.0)$ & $2(3.2)$ & 0.3336 \\
\hline - Acquired immunodeficiency syndrome & $0(0.0)$ & $0(0.0)$ & Not applicable \\
\hline \multicolumn{4}{|l|}{ Medication } \\
\hline - Low dose aspirin & $30(31.3)$ & $8(12.7)$ & 0.0073 \\
\hline - Thienopyridine & $11(11.5)$ & $2(3.2)$ & 0.0622 \\
\hline - Cilostazol & $4(4.2)$ & $3(4.8)$ & 0.858 \\
\hline - Other antiplatelet drugs & $2(2.1)$ & $6(9.5)$ & 0.0358 \\
\hline - Warfarin & $9(9.4)$ & $1(1.6)$ & 0.0479 \\
\hline - Direct oral anticoagulants & $8(8.3)$ & $2(3.2)$ & 0.19 \\
\hline - NSAIDs & $20(20.8)$ & $10(15.9)$ & 0.4343 \\
\hline \multicolumn{4}{|l|}{ Initial assessment } \\
\hline - Hemodynamic instability & $3(3.1)$ & $2(3.2)$ & 0.986 \\
\hline - Hemoglobin (g/dL) & $11.4 \pm 2.4$ & $11.2 \pm 2.6$ & 0.6914 \\
\hline - Upper endoscopy before colonoscopy & $2(2.1)$ & $1(1.6)$ & 0.8221 \\
\hline - Early colonoscopy group & $48(50.0)$ & $31(49.2)$ & 0.922 \\
\hline
\end{tabular}


- Table 2 Endoscopic outcomes, adverse events, and clinical outcomes.

\begin{tabular}{|c|c|c|c|}
\hline Outcomes & $\begin{array}{l}\text { Expert, (\%) } \\
\mathrm{N}=96\end{array}$ & $\begin{array}{l}\text { Nonexert, (\%) } \\
\mathrm{N}=63\end{array}$ & $P$ value \\
\hline \multicolumn{4}{|l|}{ Endoscopic outcomes } \\
\hline - Aronchick scale Excellent/good/fair & $83(86.5) / 10(10.4) / 3(3.1)$ & $58(92.1) / 5(7.9) / 0(0)$ & 0.3086 \\
\hline - Cecum insertion & $92(95.8)$ & $62(98.4)$ & 0.362 \\
\hline - Completion rate of insertion without expert assist & Not applicable & $62(98.4)$ & Not applicable \\
\hline - Time to the cecum (min), mean \pm SD & $8.1 \pm 5.8$ & $11.0 \pm 7.2$ & 0.0061 \\
\hline - Total procedure time (min), mean \pm SD & $32.9 \pm 18.9$ & $34.5 \pm 14.9$ & 0.5761 \\
\hline - SRH identification & $23(24.0)$ & $11(17.5)$ & 0.3284 \\
\hline \multicolumn{4}{|l|}{ Bleeding source by Colonoscopy findings } \\
\hline - Diverticular (definite) & $16(16.7)$ & $10(15.9)$ & 0.8947 \\
\hline - Diverticular (presumptive) & $41(42.7)$ & $32(50.8)$ & 0.317 \\
\hline - Rectal ulcer & $0(0.0)$ & $0(0.0)$ & Not applicable \\
\hline - Colorectal cancer & $4(4.2)$ & $1(1.6)$ & 0.362 \\
\hline - Ischemic colitis & $8(8.3)$ & $6(9.5)$ & 0.7956 \\
\hline - Infectious colitis & $0(0.0)$ & $1(1.6)$ & 0.2156 \\
\hline - Radiation colitis & $1(1.0)$ & $0(0.0)$ & 0.4164 \\
\hline - Colonic ulcer & $0(0.0)$ & $2(3.2)$ & 0.0789 \\
\hline - Nonspecific colitis & $0(0.0)$ & $0(0.0)$ & Not applicable \\
\hline " Hemorrhoid & $3(3.1)$ & $0(0.0)$ & 0.1566 \\
\hline - Others & $11(11.5)$ & $3(4.8)$ & 0.145 \\
\hline " Unknown & $16(16.7)$ & $10(15.9)$ & 0.8947 \\
\hline - Upper gastrointestinal bleeding & $1(1.0)$ & $0(0.0)$ & 0.4164 \\
\hline Success rate of endoscopic treatment & $19 / 20(95.0)$ & $10 / 10(100)$ & 0.472 \\
\hline $\begin{array}{l}\text { Completion rate of successful endoscopic treatment } \\
\text { without expert assist }\end{array}$ & Not applicable & $63(100)$ & Not applicable \\
\hline \multicolumn{4}{|l|}{ Any adverse event } \\
\hline - Preparation-related adverse events & $33(34.4)$ & $25(39.7)$ & 0.4965 \\
\hline - Nausea/vomiting & $2(2.1)$ & $5(7.9)$ & 0.1145 \\
\hline - Abdominal pain & $1(1.0)$ & $1(1.6)$ & 1.0000 \\
\hline - Volume overload & 0 & 0 & Not applicable \\
\hline - Aspiration pneumonia & 0 & 0 & Not applicable \\
\hline - Hemorrhagic shock & $1(1.0)$ & $1(1.6)$ & 1.0000 \\
\hline - Exacerbation bleeding & $32(33.3)$ & $21(33.3)$ & 1.0000 \\
\hline - lleus & 0 & 0 & Not applicable \\
\hline - Colonoscopy related adverse events & $1(1.0)$ & $0(0.0)$ & 1.0000 \\
\hline - Hemorrhagic shock & $1(1.0)$ & $0(0.0)$ & 1.0000 \\
\hline - Perforation & $0(0.0)$ & $0(0.0)$ & Not applicable \\
\hline \multicolumn{4}{|l|}{ SeriousaAdverse events } \\
\hline - Acute myocardial infarction & 0 & $1(1.6)$ & 0.3962 \\
\hline - Bacterial cellulitis & $1(1.0)$ & 0 & 1.0000 \\
\hline
\end{tabular}


- Table2 (Continuation)

\begin{tabular}{|c|c|c|c|c|c|}
\hline \multirow{2}{*}{$\begin{array}{l}\text { Outcomes } \\
\text { Clinical outcome }\end{array}$} & \multicolumn{2}{|c|}{$\begin{array}{l}\text { Expert, (\%) } \\
\mathrm{N}=96\end{array}$} & \multicolumn{2}{|c|}{$\begin{array}{l}\text { Nonexert, (\%) } \\
N=63\end{array}$} & \multirow[t]{2}{*}{$P$ value } \\
\hline & $\mathrm{N}$ & & $\mathrm{N}$ & & \\
\hline - Need for additional endoscopic examinations & 96 & $36(37.5)$ & 63 & $18(28.6)$ & 0.2449 \\
\hline - Need for interventional radiology & 96 & $1(1.0)$ & 63 & $0(0.0)$ & 0.4164 \\
\hline - Need for surgery & 96 & $0(0.0)$ & 63 & $0(0.0)$ & Not applicable \\
\hline - Need for transfusion during hospitalization & 95 & $6(6.3)$ & 63 & $3(4.8)$ & 0.6799 \\
\hline - Length of stay (day) ${ }^{1}$ & 96 & $8.0(6.8)$ & 63 & $6.4(3.9)$ & 0.0449 \\
\hline - 30-day rebleeding & 91 & $13(14.3)$ & 56 & $3(5.4)$ & 0.0914 \\
\hline " 30-day thrombosis events & 91 & $0(0.0)$ & 56 & $1(1.8)$ & 0.2009 \\
\hline - 30-day mortality & 92 & $0(0.0)$ & 56 & $0(0)$ & Not applicable \\
\hline
\end{tabular}

\section{Discussion}

Contrary to our hypothesis, we found that the rate of SRH identification, rate of successful endoscopic hemostasis, 30-day rebleeding rate, and AEs did not differ between the expert and nonexpert groups. In addition, we performed a subgroup analysis according to the number of years of endoscopy experience among nonexperts; however, nonexperts performed as well as experts regardless of their years of experience.

A possible explanation is that it is difficult for even experts to achieve a higher rate of SRH identification in cases of diverticular bleeding [6], which accounts for approximately $30 \%$ to $50 \%$ of cases of ALGIB [7-9], as these cases involve intermittent bleeding or spontaneous cessation of bleeding [6, 10]. Another explanation is that the completion rate of insertion by nonexperts alone was as high as $98.4 \%$, suggesting that the nonexpert group may be quite experienced.

In the present study, the length of hospital stay was significantly longer in the expert group than in the nonexpert group. In addition, the 30-day rebleeding rate in the expert group was not significantly higher than that in the nonexpert group. We believe this is because the expert group had higher proportions of patients with ischemic heart diseases, chronic heart failure, or cerebral vascular diseases. Therefore, there were more patients taking antithrombotic drugs in the expert group than in the nonexpert group, which resulted in a higher rebleeding rate in the former group. Consequently, there was a bias in selection of patients undergoing colonoscopies performed by experts. To adjust for this bias, we conducted a propensity score-weighted analysis. After propensity score weighting, we found that the insertion time of the nonexperts was longer by 3 minutes than that of the experts. However, there were no significant differences in the SRH identification rate and bleeding source as primary outcomes between the two groups. Performance of the colonoscopy by a nonexpert can lead to a significant prolongation of the cecum insertion time by 3 minutes, but the total procedure time and the rate of successful endoscopic treatment were similar between the two groups. Therefore, this prolongation of insertion time may not affect the primary outcomes, including diagnosis and endoscopic treatment. Furthermore, the performance of endoscopic therapies, such as clipping, bipolar coagulation, and band ligation, was also similar between the two groups (data not shown). Therefore, these factors may have contributed to the lack of differences in the clinical outcomes, including the 30 -day rebleeding rate and $\mathrm{AE}$ rate, between the groups.

Training operators to perform endoscopic procedures, including diagnostic and therapeutic procedures, is a key objective of endoscopy fellowships. To gain competency, trainees generally learn endoscopic procedures through hands-on experience under the supervision of experts [11]. Regarding training programs to increase the adenoma detection rate (ADR) and to decrease the incidence of overlooking interval colorectal cancer, routine monitoring colonoscopy quality metrics can be useful to improve the effectiveness of screening colonoscopies [12]. However, improving the identification of SRH is still challenging even for experts because SRH is rare, and it is even more difficult after successful endoscopic hemostasis [13]. By contrast, a greater degree of safety in the nonexpert group was shown in our study. Therefore, we believe that the endoscopic procedure performed by nonexperts for ALGIB is acceptable and can be included in the training program.

Our study has several strengths. First, our multicenter RCT is the first to evaluate the feasibility of the performance of colonoscopies by nonexpert endoscopists for patients with ALGIB. Second, we performed further investigations to explore the data in more depth. Nevertheless, there are several limitations of the study. First, patients were not randomly allocated to the expert and nonexpert groups. Second, there were no standardized criteria used to select the nonexpert endoscopists who performed colonoscopies in the participating hospitals. We also should consider the potential for selection bias, as the ex- 
- Table 3 Patient characteristics after propensity score weighting.

\begin{tabular}{|c|c|c|c|c|}
\hline Characteristics & Expert, \% & Nonexpert, \% & $P$ value & Standarized difference \\
\hline Age, mean $\pm S D$ & $67.5 \pm 10.0$ & $67.6 \pm 10.1$ & 0.966 & 0.011969 \\
\hline Sex, male (\%) & 67.6 & 67.3 & 0.971 & 0.04153 \\
\hline Body mass index, mean $\pm S D$ & $23.4 \pm 2.3$ & $23.5 \pm 2.2$ & 0.807 & 0.044433 \\
\hline \multicolumn{5}{|l|}{ Comorbidities } \\
\hline " Previous lower GI bleeding (\%) & 32.0 & 33.2 & 0.896 & 0.20694 \\
\hline - Charlson comorbidity index & $0.7 \pm 0.7$ & $0.7 \pm 0.9$ & 0.9 & 0 \\
\hline " Ischemic heart diseases (\%) & 6.8 & 7.1 & 0.943 & 0.11416 \\
\hline - Chronic obstructive pulmonary disease (\%) & 51 & 51 & 0.999 & 0 \\
\hline - Peptic ulcer (\%) & 3.6 & 4.4 & 0.825 & 0.41008 \\
\hline " Liver cirrhosis (\%) & 0 & 0 & 0.812 & 0 \\
\hline - Diabetes mellitus (\%) & 12.4 & 12.0 & 0.954 & 0.10899 \\
\hline - Chronic heart failure (\%) & 0 & 0 & 0.549 & Not applicable \\
\hline - Cerebral vascular diseases (\%) & 12.3 & 11.9 & 0.943 & 0.12952 \\
\hline - Dementia (\%) & 0 & 0 & & Not applicable \\
\hline - Collagen diseases (\%) & 5.0 & 4.7 & 0.935 & 0.1495 \\
\hline " Chronic kidney disease (\%) & 6.3 & 7.6 & 0.778 & 0.49294 \\
\hline " Leukemia (\%) & 0 & 0 & & Not applicable \\
\hline - Malignant lymphoma (\%) & 0 & 0 & & Not applicable \\
\hline - Solid cancer (\%) & 8.1 & 8.0 & 0.993 & 0.01764 \\
\hline - Metastatic cancer (\%) & 0 & 0 & & Not applicable \\
\hline - Acquired immunodeficiency syndrome & 0 & 0 & & Not applicable \\
\hline \multicolumn{5}{|l|}{ Medication } \\
\hline - Low dose aspirin & 14.0 & 14.1 & 0.983 & 0.03736 \\
\hline - Thienopyridine & 5.2 & 4.7 & 0.906 & 0.22894 \\
\hline - Cilostazol & 3.6 & 3.0 & 0.851 & 0.36283 \\
\hline - Other antiplatelet drugs & 3.4 & 3.1 & 0.94 & 0.1275 \\
\hline - Warfarin & 2.5 & 2.4 & 0.969 & 0.06442 \\
\hline - Direct oral anticoagulants & 4.4 & 3.8 & 0.875 & 0.28242 \\
\hline - NSAIDs & 17.2 & 18.5 & 0.858 & 0.31727 \\
\hline \multicolumn{5}{|l|}{ Initial assessment } \\
\hline - Hemodynamic instability & 5.6 & 4.4 & 0.783 & 0.54683 \\
\hline - Hemoglobin, g/dL & $11.9 \pm 1.5$ & $11.8 \pm 1.9$ & 0.909 & 0.058421 \\
\hline - Upper endoscopy before colonoscopy & 0 & 0 & 0.712 & 0 \\
\hline - Early colonoscopy group & 41.9 & 44.7 & 0.776 & 0.41894 \\
\hline
\end{tabular}


Table4 Endoscopic outcomes, adverse events, and clinical outcomes after propensity score weighting.

\begin{tabular}{|c|c|c|c|}
\hline Outcomes & Expert, \% & Nonexpert, \% & $P$ value \\
\hline \multicolumn{4}{|l|}{ Endoscopic outcomes } \\
\hline - Cecum insertion & 95.36 & 97.64 & 0.559 \\
\hline - Time to the cecum (min), mean \pm SD & $7.6 \pm 3.6$ & $10.6 \pm 5.8$ & 0.018 \\
\hline - Total time (min), medan \pm SD & $34.9 \pm 12.7$ & $34.7 \pm 11.9$ & 0.949 \\
\hline - SRH identification & 24.05 & 17.57 & 0.4163 \\
\hline \multicolumn{4}{|l|}{ Bleeding source by Colonoscopy findings } \\
\hline - Diverticular (definite) & 15.51 & 15.22 & 0.967 \\
\hline - Diverticular (presumptive) & 43.35 & 48.34 & 0.609 \\
\hline - Rectal ulcer & 0 & 0 & Not applicable \\
\hline - Colorectal cancer & 4.43 & 0.87 & 0.17 \\
\hline - Ischemic colitis & 10.99 & 10.97 & 0.997 \\
\hline - Infectious colitis & 0 & 2.19 & Not applicable \\
\hline - Radiation colitis & 1.02 & 0 & Not applicable \\
\hline - Colonic ulcer & 0 & 0 & Not applicable \\
\hline - Nonspecific colitis & 0 & 0 & Not applicable \\
\hline - Hemorrhoid & 4.91 & 0 & Not applicable \\
\hline - Others & 5.1 & 4.55 & 0.891 \\
\hline - Unknown & 17.84 & 20.05 & 0.779 \\
\hline - Upper gastrointestinal bleeding & 0 & 0 & Not applicable \\
\hline The success rate of endoscopic treatment & 97.14 & 100 & 0.3263 \\
\hline Completion rate of successful endoscopic treatment without expert assist & Not applicable & $63(100)$ & Not applicable \\
\hline \multicolumn{4}{|l|}{ Adverse event } \\
\hline - Preparation-related adverse events & 37.4 & 37.3 & 0.9885 \\
\hline - Nausea/vomiting & 3.1 & 8.5 & 0.2747 \\
\hline - Abdominal pain & 0.7 & 2.4 & 0.3838 \\
\hline - Volume overload & 0 & 0 & Not applicable \\
\hline - Aspiration pneumonia & 0 & 0 & Not applicable \\
\hline - Hemorrhagic shock & 0.1 & 1.9 & 0.0704 \\
\hline - Exacerbation bleeding & 36.7 & 28.4 & 0.3594 \\
\hline - lleus & 0 & 0 & Not applicable \\
\hline - Colonoscopy-related adverse events & 0.5 & 0 & Not applicable \\
\hline - Hemorrhagic shock & 0.5 & 0 & Not applicable \\
\hline - Perforation & 0 & 0 & Not applicable \\
\hline \multicolumn{4}{|l|}{ Serious adverse events } \\
\hline - Acute myocardial infarction & 0 & 2.1 & Not applicable \\
\hline - Bacterial cellulitis & 0.5 & 0 & Not applicable \\
\hline \multicolumn{4}{|l|}{ Outcome } \\
\hline - Need for additional endoscopic examinations & 33.7 & 26.6 & 0.4193 \\
\hline - Need for interventional radiology & 1.4 & 0 & 0.3146 \\
\hline - Need for surgery & 0 & 0 & Not applicable \\
\hline
\end{tabular}


- Table4 (Continuation)

\section{Outcomes}

- Need for transfusion during hospitalization

- Length of stay (day)

- 30-day rebleeding

- 30-day thrombosis events

\begin{tabular}{|l|l|l|}
\hline Expert, \% & Nonexpert, \% & P value \\
\hline 6.6 & 6.1 & 0.908 \\
\hline 7.0 & 6.1 & 0.1943 \\
\hline 15.7 & 5.39 & 0.0792 \\
\hline 0 & 2.31 & 0.3118 \\
\hline
\end{tabular}

SRH, stigmata of recent hemorrhage.

1 Summarized by mean (and SD).

Table 5 Endoscopic outcomes, adverse events, and clinical outcomes between expert group and groups with<3-year endoscopic experience.

\begin{tabular}{|c|c|c|c|}
\hline Outcomes & $\begin{array}{l}\text { Expert, (\%) } \\
\mathrm{N}=96\end{array}$ & $\begin{array}{l}<3 \text { years, }(\%) \\
N=8\end{array}$ & $P$ value \\
\hline \multicolumn{4}{|l|}{ Endoscopic outcomes } \\
\hline - Cecum insertion & $92(95.8)$ & $8(100)$ & 1 \\
\hline - Time to the cecum (min), mean \pm SD & $8.1 \pm 5.8$ & $6.8 \pm 1.9$ & 0.9949 \\
\hline - Total time (min), mean \pm SD & $32.9 \pm 18.9$ & $34.3 \pm 9.1$ & 0.3861 \\
\hline - SRH identification & $23(24.0)$ & $1(12.5)$ & 0.3585 \\
\hline \multicolumn{4}{|l|}{ Bleeding source by colonoscopy findings } \\
\hline - Diverticular (definite) & $16(16.7)$ & $1(12.5)$ & 1 \\
\hline - Diverticular (presumptive) & $41(42.7)$ & $3(37.5)$ & 1 \\
\hline - Rectal ulcer & $0(0.0)$ & $0(0.0)$ & Not applicable \\
\hline - Colorectal cancer & $4(4.2)$ & $0(0.0)$ & 1 \\
\hline - Ischemic colitis & $8(8.3)$ & $2(25.0)$ & 0.1704 \\
\hline - Infectious colitis & $0(0.0)$ & $0(0.0)$ & Not applicable \\
\hline - Radiation colitis & $1(1.0)$ & $0(0.0)$ & 1 \\
\hline - Colonic ulcer & $0(0.0)$ & $0(0.0)$ & Not applicable \\
\hline - Nonspecific colitis & $0(0.0)$ & $0(0.0)$ & Not applicable \\
\hline - Hemorrhoid & $3(3.1)$ & $0(0.0)$ & 1 \\
\hline - Others & $11(11.5)$ & $0(0.0)$ & 1 \\
\hline - Unknown & $16(16.7)$ & $2(25.0)$ & 0.6245 \\
\hline - Upper gastrointestinal bleeding & $1(1.0)$ & $0(0.0)$ & 1 \\
\hline Success rate of endoscopic treatment & $19 / 20(95.0)$ & $1 / 1(100)$ & 0.3049 \\
\hline Completion rate of successful endoscopic treatment without expert assist & Not applicable & $8(100)$ & Not applicable \\
\hline \multicolumn{4}{|l|}{ Adverse event } \\
\hline - Preparation-related adverse events & $33(34.4)$ & $3(37.50)$ & 1 \\
\hline - Nausea/vomiting & $2(2.1)$ & $1(12.50)$ & 1 \\
\hline - Abdominal pain & $1(1.0)$ & $0(0.0)$ & 0.2154 \\
\hline - Volume overload & 0 & $0(0.0)$ & Not applicable \\
\hline - Aspiration pneumonia & 0 & $0(0.0)$ & Not applicable \\
\hline - Hemorrhagic shock & $1(1.0)$ & $0(0.0)$ & 1 \\
\hline
\end{tabular}


$\checkmark$ Table 5 (Continuation)

\begin{tabular}{|c|c|c|c|}
\hline Outcomes & $\begin{array}{l}\text { Expert, (\%) } \\
\mathrm{N}=96\end{array}$ & $\begin{array}{l}<3 \text { years, }(\%) \\
N=8\end{array}$ & $P$ value \\
\hline Exacerbation bleeding & $32(33.3)$ & $2(25.0)$ & 1 \\
\hline - lleus & 0 & $0(0.0)$ & Not applicable \\
\hline - Colonoscopy related adverse events & $1(1.0)$ & $0(0.0)$ & 1 \\
\hline - Hemorrhagic shock & $1(1.0)$ & $0(0.0)$ & 1 \\
\hline - Perforation & $0(0.0)$ & $0(0.0)$ & Not applicable \\
\hline \multicolumn{4}{|l|}{ Serious adverse events } \\
\hline - Acute myocardial infarction & 0 & $0(0.0)$ & Not applicable \\
\hline - Bacterial cellulitis & $1(1.0)$ & & 1 \\
\hline \multicolumn{4}{|l|}{ Outcome } \\
\hline - Need for additional endoscopic examinations & $23(24.0)$ & $1(12.5)$ & 0.0489 \\
\hline - Need for interventional radiology & $1(1.0)$ & 0 & 0.3148 \\
\hline - Need for surgery & 0 & 0 & Not applicable \\
\hline - Need for transfusion during hospitalization & $6(6.3)$ & $1(12.5)$ & 0.605 \\
\hline - Length of stay (day) ${ }^{1}$ & 6.8 & 5.5 & 0.0346 \\
\hline - 30-day rebleeding & $13(14.3)$ & 0 & $<0.001$ \\
\hline - 30-day thrombosis events & 0 & 0 & Not applicable \\
\hline - 30-day mortality & 0 & 0 & Not applicable \\
\hline
\end{tabular}

- Table 6 Endoscopic outcomes, adverse, events and clinical outcomes in expert group and group with 3 to 6 years of endoscopic experience

\begin{tabular}{|c|c|c|c|}
\hline Outcomes & $\begin{array}{l}\text { Expert, (\%) } \\
\mathrm{N}=96\end{array}$ & $\begin{array}{l}3-6 \text { years, (\%) } \\
N=32\end{array}$ & $P$ value \\
\hline \multicolumn{4}{|l|}{ Endoscopic outcomes } \\
\hline - Cecum insertion & $92(95.8)$ & 31 (96.9) & 1 \\
\hline - Time to the cecum (min), mean \pm SD & $8.1 \pm 5.8$ & $12.5 \pm 8.7$ & 0.0012 \\
\hline - Total time (min), mean \pm SD & $32.9 \pm 18.9$ & $33.5 \pm 16.0$ & 0.8107 \\
\hline - SRH identification & $23(24.0)$ & $5(15.6)$ & 0.2827 \\
\hline \multicolumn{4}{|l|}{ Bleeding source by colonoscopy findings } \\
\hline - Diverticular (definite) & $16(16.7)$ & $5(15.6)$ & 0.8904 \\
\hline - Diverticular (presumptive) & $41(42.7)$ & $18(56.3)$ & 0.1832 \\
\hline - Rectal ulcer & $0(0.0)$ & $0(0.0)$ & Not applicable \\
\hline - Colorectal cancer & $4(4.2)$ & $1(3.1)$ & 1 \\
\hline - Ischemic colitis & $8(8.3)$ & $1(3.1)$ & 0.4487 \\
\hline - Infectious colitis & $0(0.0)$ & $1(3.1)$ & 0.25 \\
\hline - Radiation colitis & $1(1.0)$ & $0(0.0)$ & 1 \\
\hline - Colonic ulcer & $0(0.0)$ & $2(6.3)$ & 0.061 \\
\hline - Nonspecific colitis & $0(0.0)$ & $0(0.0)$ & Not applicable \\
\hline - Hemorrhoid & $3(3.1)$ & $0(0.0)$ & 0.5726 \\
\hline
\end{tabular}


- Table6 (Continuation)

\begin{tabular}{|c|c|c|c|}
\hline Outcomes & $\begin{array}{l}\text { Expert, (\%) } \\
\mathrm{N}=96\end{array}$ & $\begin{array}{l}\text { 3-6 years, (\%) } \\
N=32\end{array}$ & $P$ value \\
\hline - Others & $11(11.5)$ & $3(9.4)$ & 1 \\
\hline . Unknown & $16(16.7)$ & $3(9.4)$ & 0.3997 \\
\hline - Upper gastrointestinal bleeding & $1(1.0)$ & $0(0.0)$ & 1 \\
\hline Success rate of endoscopic treatment & $19 / 20(95.0)$ & $5 / 5(100)$ & 0.3049 \\
\hline Completion rate of successful endoscopic treatment without expert assist & Not applicable & $32(100)$ & Not applicable \\
\hline \multicolumn{4}{|l|}{ Adverse event } \\
\hline - Preparation-related adverse events & $33(34.4)$ & $3(37.50)$ & 1 \\
\hline - Nausea/vomiting & $2(2.1)$ & $1(12.50)$ & 1 \\
\hline - Abdominal pain & $1(1.0)$ & $0(0.0)$ & 0.2154 \\
\hline - Volume overload & 0 & $0(0.0)$ & Not applicable \\
\hline - Aspiration pneumonia & 0 & $0(0.0)$ & Not applicable \\
\hline - Hemorrhagic shock & $1(1.0)$ & $0(0.0)$ & 1 \\
\hline - Exacerbation bleeding & $32(33.3)$ & $2(25.0)$ & 1 \\
\hline - Ileus & 0 & $0(0.0)$ & Not applicable \\
\hline - Colonoscopy related adverse events & $1(1.0)$ & $0(0.0)$ & 1 \\
\hline - Hemorrhagic shock & $1(1.0)$ & $0(0.0)$ & 1 \\
\hline - Perforation & $0(0.0)$ & $0(0.0)$ & Not applicable \\
\hline \multicolumn{4}{|l|}{ Serious adverse events } \\
\hline - Acute myocardial infarction & 0 & $1(3.1)$ & 0.25 \\
\hline - Bacterial cellulitis & $1(1.0)$ & $0(0.0)$ & 1 \\
\hline \multicolumn{4}{|l|}{ Outcome } \\
\hline - Need for additional endoscopic examinations & $36(37.5)$ & $9(28.1)$ & 0.3165 \\
\hline - Need for interventional radiology & $1(1.0)$ & 0 & 0.3148 \\
\hline - Need for surgery & 0 & 0 & Not applicable \\
\hline - Need for transfusion during hospitalization & $6(6.3)$ & 0 & 0.0114 \\
\hline - Length of stay (day) ${ }^{1}$ & 6.8 & 6.6 & 0.1593 \\
\hline - 30-day rebleeding & $13(14.3)$ & $1(3.1)$ & 0.0197 \\
\hline - 30-day thrombosis events & 0 & $1(3.1)$ & 0.3096 \\
\hline - 30-day mortality & 0 & 0 & Not applicable \\
\hline
\end{tabular}

pert group performed much more challenging procedures. Third, there are no standardized teaching and training programs among the participating hospitals. Fourth, we could not collect data on what kind of technical advice the non-expert endoscopists received, including the selection of the appropriate endoscopy hemostasis device. This advice may have been helpful for successful hemostasis in the non-expert group. Finally, subgroup analysis according to the years of endoscopic experience included a small population and did not reach adequate statistical power.

\section{Conclusions}

In summary, we found that the performance of colonoscopies for ALGIB by nonexpert endoscopists did not yield worse clinical outcomes or reduced safety, suggesting that colonoscopy for ALGIB may be a feasible advanced procedure for nonexpert endoscopists to perform. 


\section{Acknowledgements}

The authors received a grant from the Japanese Gastroenterological Association Foundation. They thank all the patients and their families. They also thank Dr. Hirotsugu Watabe and Dr. Shiro Oka for help with the central review; Mariko Takeda (data management), Yumi Tanaka and Ai Okazaki (clinical monitoring planning and monitoring), Ikue Wada (clinical monitoring), Maki Kobayashi (trial coordinator), and Yuki Kusaka (audit); Dr. Tomohiro Tada for help with providing anonymization software for the central review, and the trial investigators for their roles in the trial: Dr. Aya Sugimoto of Toyonaka Municipal Hospital; Dr. Yoshihiro Hirata, Dr. Nobutake Yamamichi, Dr. Shinyama Kodashima, Dr. Satoshi Ono, Dr. Yosuke Tsuji, Dr. Shuntaro Yoshida, Dr. Keiko Niimi, Dr. Yoku Hayakawa, Dr. Takeshi Yoshikawa, Dr. Hiroto Kinoshita, Dr. Yumiko Ota, Dr. Takayuki Shinpo, Dr. Yoshiki Sakaguchi, Dr. Yu Takahashi, Dr. Sozaburo Ihara, Dr. Itaru Saito, Dr. Yosuke Kataoka, Dr. Ayako Nakada, Dr. Hikaru Kakimoto, Dr. Chihiro Takeuchi, Dr. Yuta Matsumoto, Dr. Seiichi Yakabi, Dr. Hiroya Mizutani, Dr. Daisuke Ohki, Dr. Kenta Gondo, Dr. Mitsuru Konishi, Dr. Rei Ishibashi, Dr. Tomonori Aoki, and Dr. Itsuko Hirayama of The University of Tokyo; Dr. Kohei Hayashi and Dr. Ryousuke Hirata of Nagasaki Harbor Medical Center City Hospital; Dr. Kenkei Hasatani of Fukui Prefectural Hospital; Dr. Takashi Ikeya, Dr. Kenji Nakamura, and Dr. Katsuyuki Fukuda of St. Luke's International Hospital; Dr. Hisashi Doyama, Dr. Ryosuke Ota and Dr Akihiro Dejima of Ishikawa Prefectural Central Hospital; Dr Takeyoshi Minagawa, Dr. Yutaka Okagawa, Dr Ryoji Fujii, and Dr Masahiro Yoshida of Tonan Hospital; Dr. Yusuke Kanari of Otaru Ekisaikai Hospital; and Dr Hirotsugu Saiki of Japan Community Healthcare Organization Osaka Hospital.

\section{Competing interests}

The authors declare that they have no conflict of interest.
References

[1] Niikura R, Nagata N, Aoki T et al. Predictors for identification of stigmata of recent hemorrhage on colonic diverticula in lower gastrointestinal bleeding. J Clin Gastroenterol 2015; 49: e24-30

[2] Walsh CM, Umar SB. ASGE Training Committee,. et al. Colonoscopy core curriculum. Gastrointest Endosc 2020; 93: 297-304

[3] Niikura R, Nagata N, Yamada A et al. Efficacy and safety of early vs elective colonoscopy for acute lower gastrointestinal bleeding. Gastroenterology 2020; 158: 168-175 e166

[4] Niikura R, Nagata N, Yamada A et al. A multicenter, randomized controlled trial comparing the identification rate of stigmata of recent hemorrhage and rebleeding rate between early and elective colonoscopy in outpatient-onset acute lower gastrointestinal bleeding: study protocol for a randomized controlled trial. Trials 2018; 19: 214

[5] Aronchick CA. Bowel preparation scale. Gastrointest Endosc 2004; 60: 1037-1038; author reply 1038-1039

[6] Niikura R, Nagata N, Doyama $\mathrm{H}$ et al. Current state of practice for colonic diverticular bleeding in 37 hospitals in Japan: A multicenter questionnaire study. World J Gastrointest Endosc 2016; 8: 785-794

[7] Gostout C], Wang KK, Ahlquist DA et al. Acute gastrointestinal bleeding. Experience of a specialized management team. J Clin Gastroenterol 1992; 14: 260-267

[8] Browder W, Cerise E], Litwin MS. Impact of emergency angiography in massive lower gastrointestinal bleeding. Ann Surg 1986; 204: 530536

[9] Gayer C, Chino A, Lucas C et al. Acute lower gastrointestinal bleeding in 1,112 patients admitted to an urban emergency medical center. Surgery 2009; 146: 600-606; discussion 606-607

[10] Urabe M, Nishida T, Shimakoshi $\mathrm{H}$ et al. Distinct clinical factors in hospitalized patients with diverticular bleeding and diverticulitis. Digestion 2019; 99: 239-246

[11] Patel SG, Keswani R, Elta G et al. Status of competency-based medical education in endoscopy training: a nationwide survey of US ACGMEaccredited gastroenterology training programs. Am J Gastroenterol 2015; 110: 956-962

[12] Lam AY, Li Y, Gregory DL et al. Association between improved adenoma detection rate and interval colorectal cancer rates after a quality improvement program. Gastrointest Endosc 2020; 92: 355-364.e5

[13] Nagata N, Niikura R, Aoki T et al. Risk factors for adverse in-hospital outcomes in acute colonic diverticular hemorrhage. World J Gastroenterol 2015; 21: 10697-10703

\section{CORRECTION}

Tsutomu Nishida, Ryota Niikura, Naoyoshi Nagata et al. Feasibility and safety of colonoscopy performed by nonexperts for acute lower gastrointestinal bleeding: post hoc analysis

Endoscopy International Open 2021; 09: E943-E954.

DOI: 10.1055/a-1464-0809

In the above mentioned article an author name was corrected. Correct is: Ryota Niikura. 